\title{
CONSTRUÇÃO MORAL DO ESTUDANTE DE GRADUAÇÃO EM ENFERMAGEM COMO FOMENTO DA HUMANIZAÇÃO DO CUIDADO ${ }^{1}$
}

\author{
Liziani Iturriet Avila², Rosemary Silva da Silveira ${ }^{3}$, Paula Pereira de Figueiredo ${ }^{4}$, Joel Rolim Mancia ${ }^{5}$, Naiane \\ Glaciele da Costa Gonçalves ${ }^{6}$, Jamila Geri Tomaschewski Barlem ${ }^{7}$
}

${ }^{1}$ Artigo extraído da tese - Construção moral dos estudantes de graduação em enfermagem como instrumento para a humanização do cuidado, apresentada ao Programa de Pós-Graduação em Enfermagem (PPGEnf) da Universidade Federal do Rio Grande (FURG), em 2015.

${ }^{2}$ Doutora em Enfermagem. Docente da Escola de Enfermagem da FURG. Rio Grande, Rio Grande do Sul, Brasil. E-mail: 1.iturriet@ yahoo.com.br

${ }^{3}$ Doutora em Enfermagem. Docente da Escola de Enfermagem da FURG. e do PPGEnf/FURG. Rio Grande, Rio Grande do Sul, Brasil. E-mail: anacarol@mikrus.com.br

${ }^{4}$ Doutora em Enfermagem. Docente da Escola de Enfermagem da FURG. Rio Grande, Rio Grande do Sul, Brasil. E-mail: paulapfigueiredo@yahoo.com.br

${ }^{5}$ Doutor em Enfermagem. Docente da Universidade do Vale do Rio dos Sinos. Rio Grande, Rio Grande do Sul, Brasil. E-mail: joelmancia@uol.com.br

${ }^{6}$ Mestranda do PPGEnf/FURG. Bolsista da CAPES. Rio Grande, Rio Grande do Sul, Brasil. E-mail: naianeglaciele@gmail.com

${ }^{7}$ Doutora em Enfermagem. Docente da Escola de Enfermagem e do PPGEnf/FURG. Rio Grande, Rio Grande do Sul, Brasil. E-mail: jamila_tomaschewski@hotmail.com

\section{RESUMO}

Objetivo: refletir sobre como a construção moral do estudante de graduação em enfermagem pode fomentar a humanização do cuidado. Método: trata-se de uma reflexão teórica pautada em duas diferentes correntes: piagetina e a kohebergina.

Resultados: mencionam-se como possíveis encaminhamentos desta reflexão: o reconhecimento da dimensão moral do cuidado; a necessidade de considerar a cultura dos sujeitos envolvidos no cuidado; a superação do tecnicismo na enfermagem, contemplando-se também a dimensão ética do cuidado e, finalmente, a instrumentalização de docentes para que sejam habilitados a trabalhar a moralidade humana como um exercício de cidadania em todos os momentos acadêmicos.

Conclusão: acredita-se que a formação acadêmica em enfermagem dedicada à construção moral pode auxiliar na constituição de um enfermeiro capaz de cuidar de maneira humanizada.

DESCRITORES: Enfermagem. Ética. Desenvolvimento moral. Humanização da assistência. Educação em enfermagem.

\section{CONSTRUCTION MORAL THE GRADUATE STUDENT IN NURSING AS PROMOTION HUMANIZATION CARE}

\begin{abstract}
Objective: to reflect on how the moral construction of the undergraduate nursing student can promote the humanization of care.

Method: this is a theoretical reflection based on two different frameworks: Piaget and Kohlberg.

Results: the following are mentioned as possible consequences of this reflection: the recognition of the moral dimension of care; the need to consider the culture of the subjects involved in care; overcoming technicality in nursing, also considering the ethical dimension of care and, finally, the provision of instruments to teachers in order to enable them to address human morality as an exercise of citizenship at all academic times.

Conclusion: we believe that academic nursing education dedicated to the moral construction can help to prepare nurses who are capable of humanized care.
\end{abstract}

DESCRIPTORS: Nursing. Ethics. Moral development. Humanization of assistance. Education, Nursing. 


\section{DESARROLLO MORAL DEL ESTUDIANTES DE POSTGRADO EN ENFERMERÍA COMO INSENTIVO PARA HUMANIZACIÓN DE LA ATENCIÓN}

\section{RESUMEN}

Objetivo: reflexionar sobre cómo la construcción moral del estudiante de enfermería, de grado, puede promover la humanización de la atención.

Método: se trata de un estudio reflexivo que

Resultados: se mencionan como posibles referencias de esta reflexión: el reconocimiento de la dimensión moral de la atención; la necesidad de considerar la cultura de los sujetos involucrados en el proceso; la superación de tecnicismo en la enfermería, también es contemplada la dimensión ética de la atención y, por fín, la instrumentalización a los profesores para que sean capaces de trabajar, a lo largo del momento académico, la moralidad humana como un ejercicio de la ciudadanía.

Conclusión: se cree que la educación de enfermería académica dedicada a la construcción moral puede ayudar en la creación de un enfermero capaz de cuidar de manera humana.

DESCRIPTORES: Enfermería. Ética. Desarrollo moral. Humanización de la atención. Educación en enfermería.

\section{INTRODUÇÃO}

A humanização pode ser pensada como um princípio do cuidado, que tem por finalidade organizar as ações dos trabalhadores da saúde e construir valores humanos capazes de resgatar a dignidade das pessoas que estão sendo assistidas. Do ponto de vista ético, a humanização refere-se "à reflexão crítica que cada um de nós, profissionais da saúde, tem o dever de realizar, confrontando os princípios institucionais com os próprios valores" ${ }^{1: 255}$ A ética pode ser um importante instrumento no que se refere à humanização, pois, através de seus princípios, é possível entender o que se considera bom e justo na sociedade, e o que representa o certo e o errado nas formas de cuidar.

Para aprender a cuidar de maneira humanizada, não basta instrumentalizar-se de técnicas durante a graduação, é preciso construir-se e desconstruir-se permanentemente. Nesse contexto, torna-se necessário que o docente seja capaz de reforçar no estudante valores morais que contribuam para reflexão, conscientização e (des)construção do modo de ver/pensar do estudante no que se refere ao respeito aos direitos humanos. ${ }^{1}$ A proposta do Ministério da Saúde através da Política Nacional de Humanização (PNH), também conhecida como HumanizaSUS, evidencia que a humanização não se refere a atitudes de benevolência ou bondade, mas representa o respeito aos direitos dos pacientes e o respeito aos aspectos éticos. ${ }^{2}$

Para tanto, "devemos tomar cuidado para não banalizar o que a proposição de uma Política de Humanização traz ao campo da saúde", pois "as iniciativas se apresentam, em geral, de modo vago e associadas a atitudes humanitárias, de caráter filantrópico, voluntárias e reveladoras de bondade, um 'favor', portanto, e não um direito à saúde" . ${ }^{2: 6} \mathrm{Sa}$ - be-se que humanizar é mais do que ser bondoso, no entanto se necessita associar o respeito aos direitos humanos, propostos na $\mathrm{PNH}$, aos valores humanos e morais a fim de que se concretize um cuidado humanizado, pois "na vertente moral, a humanização pode evocar valores humanitários, como respeito, solidariedade, compaixão, empatia". 1:255

Desse modo, torna-se necessário que, desde a formação acadêmica, o estudante seja instigado a se fortalecer moralmente, através de aulas teóricas, teórico-práticas e práticas em que o estudante seja colocado frente à realidade profissional e, assim, possa perceber que grande parte das decisões do cotidiano de trabalho da enfermagem tem implicações morais. O estudante necessita de preparo para resolver conflitos de maneira ética, reconhecendo o que é certo e o que é errado, para fornecer o mais alto nível de benefício ao paciente, unindo qualidade em assistência e humanização, bem como tendo competência ética. ${ }^{3-4}$

Não basta simplesmente o conhecimento do que precisa ser feito tecnicamente, se as atitudes dos estudantes forem insensíveis. É preciso, pois, comprometer-se com o cuidado, porque, ao cuidar, o estudante (futuro profissional da saúde) imprime suas "marcas pessoais nas suas ações, e essas expressam valores e sentimentos" 5:312 que o conduzem a prestar um cuidado humanizado. É necessário que os estudantes se disponham a um senso de dever, com responsabilidade e compromisso; a imergir em um processo de (des)construção para alcançar o fazer ético. Para tanto, é imprescindível confrontar valores morais e princípios éticos com a finalidade de fundamentar seu modo de ser comprometido moralmente. ${ }^{6}$

Em um estudo referente às contribuições da educação ética para a competência moral dos estudantes de enfermagem, evidenciou-se que a educação moral e ética deve estar fundamentada na prática 
clínica real. Assim, a construção moral na formação acadêmica pode acontecer através da oportunidade de articular os saberes técnicos às competências morais para que essas se revertam em humanização do cuidado. Essa busca pode ser construída articulando-se teoria e prática por meio da contextualização das temáticas em sala de aula, procurando simular vivências para que o estudante possa colocar-se em situações de tomadas de decisão. ${ }^{6}$

Acredita-se que a construção moral possa ser desenvolvida a partir de valores e comportamentos internalizados em diversos contextos vivenciados e que o comprometimento moral pode ocorrer a partir da internalização de valores e atitudes valorativas no processo de formação dos estudantes de Enfermagem. Não só o ambiente de formação mas também as pessoas, o país, a região, a cidade, a religião, o trabalho, a cultura, o modo de viver, de falar, o temperamento, o modo de ser e de exercer a liberdade podem ser a base sobre a qual se constrói a moralidade de um indivíduo. ${ }^{7}$

Nessa perspectiva, o processo de formação do enfermeiro não pode ser pensado sem levar em consideração as perspectivas éticas, que constituem a base do desenvolvimento da enfermagem. Para tanto, a graduação deve prezar pelo aprender a aprender através de uma formação crítica e integradora, comprometida com o cuidado humanizado, responsável e ético. ${ }^{8}$ Acredita-se que, ao investir na construção moral de estudantes de enfermagem, seja possível estabelecer uma enfermagem mais solidária e mais humanizada, a partir da apropriação de conhecimentos científicos e da internalização de valores morais para embasar a prática profissional.

A partir dessas afirmações, objetivou-se refletir acerca de como a construção moral do estudante de graduação em enfermagem pode fomentar a humanização do cuidado. Para o alcance desse objetivo, inicialmente se expõe acerca do processo de desenvolvimento e construção moral, através das concepções de Piaget ${ }^{9}$ e Kohlberg, ${ }^{10}$ pesquisadores pioneiros no que se refere ao entendimento de como ocorre o processo de desenvolvimento e construção moral. Posteriormente, reflete-se sobre a humanização do cuidado e a formação moral do estudante de graduação em enfermagem, e, para elucidar sobre como a graduação em enfermagem fundamentada na construção moral pode humanizar o cuidado, finaliza-se essa teorização com esclarecimentos em torno da educação como elemento de (des)construção moral.

Foi realizada uma reflexão teórico-filosófica, a qual se fundamenta em formulações teóricas aprofundadas acerca de uma temática específica. ${ }^{11}$ Nesse contexto, reflete-se sobre como a construção moral do estudante de graduação em enfermagem pode fomentar a humanização do cuidado.

A presente reflexão apresenta como subsídio teórico, duas diferentes correntes de pensamento acerca do desenvolvimento moral, as correntes: piagetiana e a kohlberguiana. Adicionalmente, destacam-se os espaços em que a moralidade pode ser trabalhada e/ ou construída; reflete-se sobre como a humanização do cuidado pode ser influenciada pela formação moral do estudante de graduação em enfermagem e por fim, teoriza-se sobre a educação como elemento de (des)construção moral.

\section{PROCESSO DE DESENVOLVIMENTO E CONSTRUÇÃO MORAL}

No que tange aos estudos sobre a moralidade humana, Piaget e Kohlberg são os pioneiros em buscar entender como ocorre o processo de desenvolvimento e construção moral. O primeiro autor, investigou o desenvolvimento moral das crianças, e o segundo realizou pesquisas com adolescentes e adultos. Assim, pode-se dizer, então, que há duas correntes de pensamento acerca do desenvolvimento moral que, de alguma forma, são complementares: o referencial piagetiano e o referencial kohlberguiano. ${ }^{12}$

\section{A construção moral piagetiana}

Jean Piaget é considerado uma referência no que concerne ao estudo do desenvolvimento moral, principalmente por ter instaurado questões desenvolvimentistas como maneira de pesquisar sobre a moralidade humana, estabelecendo estágios para a construção moral. Ressalta-se que Piaget trouxe para a filosofia uma importante contribuição, pois fez com que fossem realizadas investigações sobre como ocorre o desenvolvimento moral. Seu feito foi aplicar algo filosófico no campo empírico. ${ }^{13}$

A importância do autor encontra-se em sua ênfase sobre os problemas referentes à aquisição e à transformação do raciocínio moral na criança. Destaca-se que o pesquisador tem como um de seus postulados que a moral se desenvolve, gradualmente, na criança, quando essa vai se adaptando aos valores e regras que são impostos pela sociedade e pela cultura a que pertence. ${ }^{14}$

Na obra Juízo Moral da Criança, o autor define moralidade como a relação de obediência ou desobediência estabelecida pelos indivíduos em relação a determinados sistemas de regras e 
normas sociais. A criança inicialmente precisa ser ordenada para que tome atitudes e à medida que algumas condições psicológicas vão se estabelecendo, a criança vai se tornando capaz de raciocinar logicamente e de tomar decisões morais através de seu próprio senso crítico. Dessa forma, torna-se capaz de tomar decisões livres e esclarecidas, podendo, então, ser considerada como um indivíduo moralmente autônomo. ${ }^{9}$

Para concretizar suas pesquisas sobre desenvolvimento moral, o estudioso examina crianças no contexto de jogos infantis. Através da observação de situações lúdicas e também da realização de entrevistas, o pesquisador encontra a possibilidade de analisar como ocorre o processo de construção do raciocínio moral, verificando como as crianças se comportam em disputas com outras crianças. Essas situações de embate colocam os valores das pessoas em prova; como elas agem quando estão perdendo? como agem quando estão ganhando? conseguem competir honestamente? ${ }^{9}$

Piaget apresenta três fases sucessivas de desenvolvimento para o julgamento moral, a anomia, a heteronomia e a autonomia moral; resumidamente tem-se que a anomia caracteriza as crianças de até um ano e meio, que ainda são fortemente egocêntricas e não diferenciam o que é certo e o que é errado, sendo incapazes de seguir regras sociais. Nessa fase, o tipo mais forte de relação que estabelecem é a de afeto pelos pais. A heteronomia é caracterizada como a fase em que surge o respeito às regras exteriores à criança. Ditadas de forma coercitiva, essas regras são impostas por pessoas mais velhas. A criança não cumpre regras por sentir que é importante, mas por temer punição. A autonomia moral caracteriza-se pela fase em que o sujeito consegue obter senso crítico, sendo capaz de optar por caminhos próprios, sem precisar obedecer a alguém para realizar uma ação. Percebe, por si mesmo, atitudes consideradas corretas ou incorretas e é livre para escolher de maneira esclarecida o caminho a ser percorrido.

Além de descrever como ocorre a construção moral dos indivíduos durante o período da infância, o autor identificou duas formas de moralidade distintas que têm repercussões na vida moral adulta. O primeiro desses dois processos é a moral que surge por imposição ou por limitações impostas pelos adultos, que leva à heteronomia moral e, por consequência, muitas vezes o sujeito passa sua vida adulta sem conseguir ser autônomo em suas decisões morais. A segunda forma de moralidade fundamenta-se na cooperação, fazendo surgir a moral autônoma. ${ }^{12}$
Desde a infância, os indivíduos vão construindo-se moralmente, buscando agir de acordo com padrões culturais e seguindo regras de convívio social. A construção moral não ocorre somente durante a infância mas também na fase adulta através dos princípios éticos compartilhados com a família, amigos e instituições de ensino. ${ }^{7}$ Cabe destacar que a graduação em enfermagem parece ser um espaço que pode favorecer a construção moral com foco no processo saúde-doença e para além dele, pois esse curso propicia diversos momentos de discussões éticas, em que o educando é convidado a refletir sobre questões morais no cuidado aos enfermos.

\section{A construção moral kohlberguiana}

Em um sentido semelhante ao das pesquisas piagetianas, emergem os estudos de Lawrence Kohlberg com a Teoria dos Níveis de Desenvolvimento Moral. ${ }^{10}$ A descrição do desenvolvimento moral proposta nessa Teoria sobrepõe-se parcialmente à de Piaget, mas se prolonga até a adolescência e a idade adulta. Para explorar o raciocínio sobre questões morais, o pesquisador utilizou uma série de dilemas hipotéticos criados por ele mesmo para questionar os sujeitos de seus estudos. Os participantes deveriam avaliar e se posicionar frente a tais dilemas, justificando suas posições. Assim, o autor concluiu que existem três níveis principais de raciocínio moral, sendo cada nível composto por dois estágios, a saber: nível pré-convencional, convencional e pós-convencional.

No nível pré-convencional está o primeiro estágio, que contempla a moralidade heterônoma, e o segundo estágio, que vem a ser a moralidade individualista/instrumental. Nesse nível, não houve ainda uma internalização de valores e princípios morais, considerando-se uma fase pré-moral, na qual o indivíduo apresenta um forte hedonismo, em que a satisfação individual comanda as ações da pessoa. Assim, o indivíduo tem suas ações regidas pela obediência decorrente do medo de sofrer punições. Nesse primeiro nível, encontram-se a maioria das crianças com idade abaixo de nove anos.

O nível convencional, por sua vez, compreende o terceiro estágio, que marca a moralidade normativa interpessoal, e o quarto estágio, a moralidade do sistema social. Esse é o nível de internalização de valores morais, havendo um maior entendimento do indivíduo em relação aos seus papéis na sociedade. Dessa maneira, o modo de agir ocorre pela subordinação dos interesses pessoais em detrimento das leis estabelecidas pela sociedade; nesse nível, o indivíduo é capaz de respeitar a ordem social. 
Encontram-se no nível convencional a maior parte dos adolescentes e dos adultos. ${ }^{10}$

Já o nível pós-convencional contempla o quinto estágio, em que há a moralidade dos direitos humanos, e o sexto estágio, no qual a moralidade dos princípios éticos universais está presente. Nesse nível, encontra-se, pela primeira vez, o questionamento acerca do que é legal e do que é moral. O indivíduo é capaz de reconhecer que as leis podem ser injustas, despontando a percepção do conflito entre as esferas da lei e da justiça. No nível pósconvencional, o pesquisador visualiza apenas uma pequena parcela da sociedade. Para estar nesse nível, de acordo com a Teoria, há uma idade mínima de vinte anos. ${ }^{10}$

Estudiosos que se aprofundaram na Teoria dos Níveis de Desenvolvimento Moral, destacam suas características estruturais, de modo que os estágios refletem maneiras de raciocinar moralmente; assim, qualquer pessoa pode ser classificada em qualquer um dos níveis estabelecidos, através de suas respostas e de suas justificativas. Os resultados das pesquisas permitiram a Kohlberg concluir que, apesar de possíveis diferenças quanto à idade em que os indivíduos alcançam cada estágio, há uma sequência universal de estágios. Quanto ao caso de raciocínio moral, não se detectam diferenças de cultura para cultura ou entre diferentes religiões e crenças. ${ }^{12}$

Após a exposição acerca de estudos que revelam como ocorre o desenvolvimento e a construção moral da pessoa, torna-se possível entender que, tanto Piaget quanto Kohlberg, concluem que existe um processo de desenvolvimento moral que faz com que o ser humano se torne capaz de fazer parte de um convívio social harmonioso, assumindo valores que regulam seu modo de ser e de agir perante as outras pessoas e perante a sua própria vida. Essa capacidade faz com que o indivíduo diferencie o que é certo ou errado, que desenvolva senso crítico perante as injustiças e, por fim, que tome decisões livres e autônomas, baseadas em concepções moralmente aceitas. ${ }^{12-13}$

Cabe ainda destacar que a construção moral ocorre do início ao final da vida e pode ser oportunizada por diversas vivências do ser humano. Pode-se afirmar que, na enfermagem, "durante a formação profissional, os estudantes que estão em diferentes estágios ou mesmo em diferentes níveis de desenvolvimento do julgamento moral, podem progredir para estágios ou níveis mais elevados", 14:938 desde que seja possível que docentes e discentes discutam temáticas éticas e morais em disciplinas teóricas e que seja oportunizada a experiência de cuidar de maneira humanizada, refletindo-se sobre a dimensão moral do cuidado de enfermagem.

\section{REFLETINDO A HUMANIZAÇÃO DO CUIDADO E A FORMAÇÃO MORAL DO ESTUDANTE DE GRADUAÇÃO EM ENFERMAGEM}

Em busca de refletir sobre a temática do cuidado no campo da enfermagem, evidenciam-se algumas ideias centrais para a formação moral do estudante de enfermagem e a humanização do cuidado. Para que o estudante de enfermagem possa cuidar de modo humanizado, é necessário não somente o cumprimento de ações gerenciais, administrativas e assistenciais mas também o ato de oportunizar ao estudante a possibilidade de vincular o conhecimento técnico-científico, a competência e a destreza técnica à habilidade para promover relações interpessoais favoráveis entre si, com docentes, usuários, familiares e demais trabalhadores da saúde. ${ }^{7,15}$

A realização de procedimentos está inserida no processo de cuidado, mas tão importante quanto o desenvolvimento de habilidades técnicas durante a graduação, é a possibilidade de resgatar a sensibilidade moral do estudante. ${ }^{7,15}$ Estudos demonstram que a competência moral deve ser considerada importante no processo formativo em enfermagem, sendo um processo que continua durante todo o programa de educação, de maneira transversal nas disciplinas de graduação, em que os estudantes gradativamente aumentam sua confiança e sua capacidade de refletir moralmente sobre situações específicas. Esse tipo de reflexão levará o discente a um melhor entendimento da prática de enfermagem. ${ }^{16}$

Para contemplar a humanização do cuidado, foi lançada, em 2003, a PNH ou HumanizaSUS, que "aposta na inclusão de trabalhadores, usuários e gestores na produção e gestão do cuidado e dos processos de trabalho". ${ }^{17: 4}$ A PNH considera que, havendo comunicação entre esses três eixos (trabalhadores, gestores e usuários), haverá mudança para melhor no que se refere à saúde pública. Segundo a $\mathrm{PNH}$, "humanizar se traduz, então, como inclusão das diferenças nos processos de gestão e de cuidado. Tais mudanças não são construídas por uma pessoa ou grupo isolado, mas de forma coletiva e compartilhada". 17:4

Embora já consagrada, a PNH continua sendo alvo de muitos questionamentos, sobretudo no que diz respeito ao cuidado de enfermagem, uma vez que a essência da área remete ao cuidar. O próprio 
Código de Ética dos Profissionais de Enfermagem expressa a necessidade de que seus trabalhadores exerçam a profissão com justiça, compromisso, equidade, resolutividade, dignidade, competência, responsabilidade, honestidade e lealdade, ressaltando a dimensão ética que esse tema implica. ${ }^{18}$

Entretanto, apesar de parecer óbvia a ideia de que o serviço prestado aos seres humanos é humanizado por sua própria natureza, sabe-se que, na prática, pode não estar ocorrendo dessa forma. Mesmo passada mais de uma década da implementação da $\mathrm{PNH}$, a questão da humanização do cuidado continua a ser alvo de debates e parece necessitar de novas estratégias para que seja realmente efetivada. Talvez isso ocorra porque discutir sobre o cuidado instiga inúmeros questionamentos acerca de como a enfermagem vem realizando a prática de assistência clínica. Como a PNH abriu espaço para pensar o cuidado, e a essência da enfermagem caracteriza-se pelo cuidado (e esse por sua vez não está dissociado da humanização) torna necessário pensar, então, em que medida o cuidado tem de ser mais humanizado. ${ }^{19}$

As diretrizes da PNH estão para além de um simples conjunto de regras para nortear as práticas em saúde, podendo ser entendidas como um guia de conduta a ser perseguido por todos os trabalhadores que têm sua formação em saúde. Uma conduta humanizada pressupõe a adoção de um comportamento profissional que consiga visualizar o ser humano em seus diversos âmbitos, valorizando suas crenças, sua cultura, sua religião e seus valores morais. Nesse sentido, com a implementação de um novo paradigma, é esperado que ocorram mudanças no setor da saúde, deixando para trás o que ainda persiste: "um modelo de atenção biomédico, com frágeis relações entre usuários e equipe de saúde e a precarização do acesso aos serviços" . 20:307

$\mathrm{Na}$ enfermagem, assim como nas demais profissões de saúde, há um componente humano e um componente mecânico, esse representado pelas intervenções técnicas ligadas ao cuidado. O componente humano está representado pelos valores fundamentais da enfermagem, tais como "a solidariedade, o valor da verdade, a moralidade, e a utilidade".${ }^{21: 904}$ Esse componente comporta ainda, a atenção, o desvelo, a observação constante, o preparo contínuo para o enfrentamento de situações adversas e a responsabilidade, para chegar ao fim almejado, a humanização. ${ }^{21}$

Todos esses adjetivos culminam na atitude humanizada perante os usuários. De acordo com a PNH, a humanização é uma orientação ética e polí- tica para nortear o enfrentamento dos problemas de saúde, implicando uma atitude ética "de usuários, gestores e trabalhadores de saúde comprometidos e corresponsáveis" 22:13 pelo cuidado do outro, o que pressupõe "uma ligação afetiva e moral entre ambos". 22:13

\section{A EDUCAÇÃO COMO ELEMENTO DE (DES)CONSTRUÇÃO MORAL}

A educação deve ser um ato construído por sujeitos que ensinam e aprendem através do estabelecimento de relações dialógicas. Pode-se afirmar que a educação não somente constrói conhecimentos mas também edifica o indivíduo como sujeito moral, pois, quando "se respeita a natureza do ser humano, o ensino dos conteúdos não pode se dar alheio à formação moral do educando". $23: 16$ Assim, parece ser fundamental que o educador esteja atento para a tentativa de instigar no educando uma postura crítica acerca da vida e reflexiva acerca de si mesmo a fim de que possa se tornar, através da educação moral, uma pessoa esclarecida, autônoma e ética.

A educação moral é entendida como um "processo pelo qual os valores deixam de serem leis impostas por agentes externos e se convertem em diretrizes internas, legitimadas pela própria pessoa" ${ }^{24: 456}$ Para que esse processo ocorra dessa maneira, a educação deve ser libertadora, proporcionando, assim, autonomia aos sujeitos. Idealizase que o educador possa ajudar o educando a se libertar de convenções sociais, do autoritarismo, da obediência impensada e do comodismo. Para tanto, a formação deve estimular a ação do sujeito para a construção de conhecimentos, propiciando a criticidade, a reflexão e a legitimação de valores morais.

No que se refere à educação diretamente aplicada à enfermagem, pode-se inferir que Paulo Freire apresenta em seus pressupostos conceitos que podem ser considerados importantes para a formação do estudante de enfermagem, no tocante à sua construção moral e ao aprendizado da humanização do cuidado, são eles: diálogo, problematização, liberdade e conscientização. Além disso, "o processo pelo qual se chega a uma atitude crítica e reflexiva seria por um percurso problematizador; e qualquer forma de aprendizagem sem liberdade não subsiste". 25:634

O diálogo, entendido como "o caminho pelo qual os homens encontram seu significado enquanto homens", 26:8 é considerado como uma necessidade existencial, que possibilita ao ser humano estabelecer relações. No que concerne à enfermagem, ressalta- 
se que, possivelmente, o diálogo pode ser um meio para incentivar os educandos a adotarem práticas compatíveis com a ideologia do cuidado de enfermagem e não apenas com as normas institucionais estabelecidas no local em que irão trabalhar.

A problematização parte de situações concretas e reais do cotidiano dos estudantes que necessitam ser questionadas, revistas, discutidas e analisadas em uma tentativa de provocar novos modos de pensar e de agir. O objetivo maior dessa reflexão deve ser a possibilidade de o estudante transformar a si e a realidade. Através da problematização, o educador pode convidar os educandos a refletirem criticamente sobre sua realidade. Esse processo necessita de liberdade, elemento essencial para a aprendizagem, uma vez que, para aprender, é necessário poder criar, poder propor como e o que se deve ou se quer aprender. Já a conscientização consiste no desenvolvimento do senso crítico e reflexivo, na tomada de consciência que ocorre no interior de cada indivíduo, pois o ato de ter consciência deve partir do próprio sujeito, ninguém o fará por ele. ${ }^{26}$

Ao buscar uma educação baseada no diálogo, na problematização, na liberdade e na conscientização, a enfermagem, possivelmente, formará profissionais capazes de assistir de maneira humanizada, pois o ato de cuidar requer a percepção do todo; a visualização do ser sob uma ótica holística, criativa e criadora. Assim, instaurar uma graduação que priorize a humanização pode contribuir para que o futuro profissional da área da saúde assista de maneira humanizada. ${ }^{27}$

Posto isso, considera-se que a educação formal é ideal para auxiliar na internalização dos valores morais. Nesse sentido, a graduação em enfermagem é um terreno fértil para discussões acerca de dilemas éticos, o que pode ajudar a consolidar os valores e as virtudes que já existem nos estudantes, e incentivar, ainda, a superação de suas imperfeições morais. Certamente, a educação formal não se caracteriza como o único espaço em que o ser se constrói moralmente, porém, a universidade parece ser um local para que ocorram discussões acerca da moralidade humana. ${ }^{8}$

Nessa perspectiva, destaca-se que uma das atribuições das universidades diz respeito à promoção da educação moral dos estudantes. Assim, "a educação tem um papel fundamental na formação do sujeito moral, crítico e autônomo, dando novos e transformadores rumos ao movimento dialético entre o indivíduo e a coletividade" $8: 745$ Há diversas maneiras de articular os saberes técnicos às competências morais para que se revertam em humanização do cuidado: essa busca pode ser construída por meio de discussões éticas, propostas no ambiente acadêmico, articulando teoria e prática através da contextualização das temáticas em sala de aula, procurando-se simular vivências com a finalidade de o estudante se colocar em ocasiões de tomadas de decisão, instrumentalizando-se para buscar soluções a problemas morais da vida real cotidiana da enfermagem.

Assim, para formar um enfermeiro capaz de cuidar de maneira humanizada, não basta evidenciar somente questões teóricas e técnicas. É preciso, pois, fomentar o olhar crítico para que o aluno tenha autonomia para (des)construir-se permanentemente a fim de resgatar valores como responsabilidade, solidariedade e compromisso com a vida. Desse modo, entende-se que a formação do estudante é fundamental para amparar questões referentes à moralidade humana, acreditando-se que durante a formação ética esses elementos podem ser contemplados.

Além de a formação favorecer a construção da moralidade, também deve estar pautada no Código de Ética dos Profissionais de Enfermagem para que se efetive um processo de assimilação de valores morais e de normas de conduta para com os usuários e com a comunidade de maneira geral. Os códigos de ética são, indiscutivelmente, relevantes, eles têm compromisso com os princípios éticos de uma profissão. Durante o processo formativo, deve-se, assim, orientar o estudante a ter compromisso com práticas éticas. Ademais, promover a consciência de que enfermeiros precisam ser capazes de trabalhar para resolver conflitos morais. ${ }^{28}$

Após essas considerações, cabe ressaltar que a formação moral do estudante de enfermagem deve ser iniciada, sempre que possível, logo no princípio do curso com noções gerais de ética, explorando princípios e fundamentos das teorias éticas, bem como problemas e dilemas éticos. De modo específico, devem ser abordados os princípios éticos em enfermagem, necessários para o processo de tomada de decisão, dentre outros. Ademais, o próprio estudante deve participar e vivenciar simulações de problemas éticos e morais, pois, conforme já foi evidenciado, não basta receber orientações passivamente, ele tem de constituir-se como sujeito ativo no processo de educação moral e de construção de si. $^{29}$

Desta forma, durante a formação acadêmica, é preciso ajudar os estudantes a reconhecerem a dimensão afetiva e moral do cuidado e orientá-los a determinarem algumas limitações individuais e morais, haja vista que a formação profissional não se restringe à habilidade técnica e à transmissão de conhecimentos teóricos, mas requer construir caminhos de referência promovendo mudanças. ${ }^{1}$ 


\section{CONCLUSÃO}

Este estudo possibilitou refletir acerca de como a construção moral do estudante de graduação em enfermagem pode fomentar a humanização do cuidado. A partir da discussão realizada, foi possível perceber que a formação acadêmica em enfermagem dedicada à construção moral pode auxiliar na constituição de um enfermeiro capaz de cuidar de maneira humanizada. Mencionamse como possíveis encaminhamentos desta reflexão: o reconhecimento da dimensão moral do cuidado; a necessidade de considerar a cultura dos sujeitos envolvidos no cuidado; a superação do tecnicismo na enfermagem, contemplando-se também a dimensão ética da profissão; e, finalmente, a instrumentalização de docentes para que sejam habilitados a trabalhar a moralidade humana como um exercício de cidadania em todos os momentos acadêmicos.

Parece ser relevante que os docentes assumam o compromisso com uma parte da construção e internalização de valores morais dos estudantes de enfermagem, reconhecendo que o ambiente de estudos é um local onde se constroem perspectivas sobre o cuidado, através do fortalecimento dos valores humanos e do olhar comprometido com o cuidado de qualidade, favorecendo a enfermagem na prestação de uma assistência humanizado.

Cabe destacar que o ato de cuidar demanda atenção para o todo, para a integralidade do ser. Durante a formação em enfermagem, necessita-se prezar por uma educação fundamentada no diálogo, na problematização de ideias e no desenvolvimento da moralidade do estudante, para que ele aprenda a priorizar, a tomar decisões, a colocar-se no lugar do outro e, assim, seja capaz de cuidar de maneira humanizada.

Este artigo destacou a necessidade de pensar aspectos referentes à competência ética e à construção moral dos estudantes de enfermagem, o que vai ao encontro de conclusões semelhantes discutidas pela literatura nacional e internacional da área. Assim, depois de tudo o que foi apresentado, destaca-se que, desde a formação acadêmica, o estudante precisa ser instigado a se instrumentalizar moralmente, simulando a vivência da realidade profissional, por meio de aulas teóricas, teórico-práticas e práticas, a fim de tornar-se fortalecido para resolver conflitos cotidianos em seu fazer profissional de maneira ética.

Esta reflexão não pretendeu esgotar o assunto proposto, nem estabelecer verdades, mas suscitar discussões que possam alicerçar algumas mudan- ças de pensamento no que se refere à formação em enfermagem, à construção moral e à humanização.

\section{REFERÊNCIAS}

1. Rios IC. Caminhos da humanização na saúde: prática e reflexão. São Paulo: Áurea Editora; 2009.

2. Ministério da Saúde (BR). Política Nacional de Humanização. Relatório Final da Oficina HumanizaSUS [Internet]. Brasília (DF): Ministério da Saúde; 2004 [cited 2015 Jun 06]. Available from: http://bvsms.saude.gov.br/bvs/publicacoes/ oficina_nac_humanizaSus.pdf

3. Solum EM, Maluwa VM,Severinsson E. Ethical problems in practice as experienced byMalawian studentnurses. Nurs Ethics.2012; 19: 128-38.

4. Rosser M, Mooney GP, Jasper M. Professional development, reflection and decision-making in nursing andhealthcare [Internet]. 2nd ed. Chichester: Wiley-Blackwel; 2013 [cited 2015 Dez 22]. Available from: http://samples.sainsburysebooks. co.uk/9781118303269_sample_406928.pdf

5. Silva FD, Chernicharo IM, Ferreira MA. Humanização e desumanização: a dialética expressa no discurso de docentes de Enfermagem sobre o cuidado. Anna Nery. 2011; 15(2):306-13.

6. Cannaerts N, Gastmans C, Casterlé BD. Contribution of ethics education to the ethical competence of nursing students: educators' and students' perceptions. Nurs Ethics 2014; 21: 861-78.

7. Silveira RS, Martins CR, Lunardi VL, Vargas MAO, Lunardi-Filho WD, Avila LI. A dimensão moral do cuidado em terapia intensiva. Ciênc Cuidado Saúde. 2014; 13(2):327-34.

8. Goergen PL. Educação moral hoje - cenários, perspectivas e perplexidades. Educaç Sociedade [Internet]. 2007 [cited 2015 Maio 20]; 28(1):737-62. Available from: http://www.scielo.br/pdf/es/ v28n100/a0628100.pdf

9. Piaget J. O Juízo Moral na Criança. São Paulo: Summus; 1994 (original 1932).

10. Kohlberg L. Essays on moral development. v. 2. The psychology of moral development. San Francisco (US): Harper and Row; 1984.

11. Pope C, Mays N, organizadores. Pesquisa qualitativa na atenção à saúde. Porto Alegre (RS): Artmed; 2009.

12. Biaggio AMB. Lawrence Kohlberg: ética e educação moral. 2. ed. SãoPaulo (SP): Moderna. 2009

13. Sampaio LR. A Psicologia e a educação moral. Psicol Ciênc Profissão. 2007; 27(4):584-95.

14. Burgatti JC, Bracialli LAD, Oliveira MAC. Ethical problems experienced in a supervised curricular internship in nursing in an integrated curriculum. Rev Esc Enferm USP [Internet]. 2013 [cited 2015 Dez 20]; 47(4):937-42. Available from: http://www.scielo.br/ pdf/reeusp/v47n4/en_0080-6234-reeusp-47-4-0937.pdf 
15. Ramos FRS, Brehmer LCF, Vargas MAO, Schneider DG, Drago LC. Ethics constructed through the process of nurse training: conceptions, spaces and strategies. Rev Latino-am Enfermagem [Internet]. 2013 [cited 2015 Dez 15]; 21 (spe): 13-21. Available from: http:// www.scielo.br/pdf/rlae/v21nspe/15.pdf

16. Solum EM, Maluwa VM, Tveit B, Severinsson E. Enhancing students' moral competence in practice: Challenges experienced by Malawian nurse teachers. Nurs Ethics. 2015; 16(spe):1-13.

17. Ministério da Saúde (BR). Política Nacional de Humanização - PNH. Brasília: Ministério da Saúde; 2013.

18. Brasil. Lei $n^{\circ} 7.498$, de 25 de junho de 1986: dispõe sobre a Regulamentação do Exercício Profissional da Enfermagem, 1986.

19. Mongiovi VG, Anjos RCCBL, Soares SBH, LagoFalcão TM. Reflexões conceituais sobre humanização da saúde: concepção de enfermeiros de Unidades de Terapia Intensiva. Rev Bras Enferm. 2014; 67(2):306-11.

20. Cotta RMM, Reis RS, Campos AAO, Gomes AP, Antonio VE, Siqueira-Batista R. Debates atuais em humanização e saúde: quem somos nós? Cienc Saúde Coletiva. 2013; 18(1):171-9.

21. Guimarães GL, Chianca TCM, Mendoza IYQ, Goveia VR, Matos SS, Viana LO. The core values of modern nursing in the light of Dilthey and Scheler. Texto Contexto Enferm [Internet]. 2015 [cited 2015 Dez 15]; 24(3): 898-905. Available from: http://www. scielo.br/scielo.php?script=sci_arttext\&pid=S010407072015000300898\&lng=en\&nrm=iso\&tlng=en
22. Ministério da Saúde (BR). Política Nacional de Humanização da Atenção e da Gestão do SUS material de apoio. Brasília (DF): Ministério da Saúde; 2006 [cited 2015 Jun 10]. Available from: http:// www.saude.sc.gov.br/hijg/gth/Cartilha\%20da\%20 PNH.pdf

23. Freire P. Pedagogia da autonomia: saberes necessários à prática educativa. 43. ed., São Paulo (SP): Paz e Terra, 2011.

24. Müller A, Alencar HM. Educação moral: o aprender e o ensinar sobre justiça na escola. Educ Pesquisa, 2012; 38(2):453-68.

25. Miranda KCL, Barroso MGT. A contribuição de Paulo Freire à prática e à educação crítica em enfermagem. Rev Latino-am Enfermagem. 2004; 12(4):631-5.

26. Freire P. Conscientização, teoria e prática da libertação: uma introdução ao pensamento de Paulo Freire. São Paulo: Centauro, 2005.

27. Chagas NR, Ramos IC, Silva LF, Monteiro ARM, Fialho AVM. Cuidado crítico y creativo: contribuciones de la educación de Paulo Freire para la enfermería. Cienc Enferma. 2009, 2(1):35-40.

28. Rosenkoetter MM, Milstead JA. A code of ethics for nurse educators: revised. Nursing Ethics [Internet]. 2010 [cited 2015 Jun 17]; 17(1):137-9.. Available from:: http://www.ncbi.nlm.nih.gov/pubmed/20089635

29. Kloh D, Lima MM, Reibnitz K.S. Ethical and social commitment in the teaching plan of nursing education. Texto Contexto Enferm [Internet]. 2014 [cited $2015 \mathrm{Dez}$ 23]; 23(2):484-91. Available from: http:/ / www.scielo. br/pdf/tce/v23n2/0104-0707-tce-23-02-00484.pdf
Correspondência: Liziani Iturrie Avila

Universidade Federal do Rio Grande

Rua Generl Osório - Campus Saúde

96201-900 - Rio Grande, RS, Brasil

E-mail:1.iturriet@yahoo.com.br
Recebido: 08 de setembro de 2015

Aprovado: 24 de maio de 2016

This is an Open Access article distributed under the terms of the Creative Commons (CC BY). 